\title{
Human Papillomavirus Infection in Sexually Active Adolescent Females: Prevalence and Risk Factors ${ }^{1}$
}

\begin{abstract}
ANNA-BARBARA MOSCICKI, JOEL PALEFSKY, JOHN GONZALES, AND GARY K. SCHOOLNIK
Departments of Pediatrics [A.-B.M.], Laboratory Medicine [J.P.], and Pathology [J.G.], University of California, San Francisco, California 94143-0314 and the Department of Medical Microbiology and Immunology [G.K.S.],
\end{abstract} Stanford University, Stanford, California 94305-5425

\begin{abstract}
We examined the prevalence of human papillomavirus (HPV) infection, and associated risk factors for infection with HPV types $6,11,16,18,31,33$, and 35 , in 661 sexually active adolescent females attending family planning clinics. Fifteen percent were positive for HPV DNA by RNA-DNA dot-blot hybridization. More than $60 \%$ of the HPV-positive subjects harbored at least one of the following cancer-related HPV types: 16, 18, 31, 33, or 35. Those with HPV had a mean range of four to $\mathbf{1 0}$ lifetime sexual partners compared with a mean range of one to three in those without HPV $(p<0.001)$. After the analysis was adjusted for number of lifetime sexual partners, no other risk factor was associated with HPV infection. We conclude that oncogenic-related HPV types are common sexually transmitted organisms found in our population. The strong relationship with number of sexual partners suggests that acquisition of HPV infection is predominantly influenced by sexual behavior. However, in our population, confounders such as oral contraceptive use, past history of Chlamydia trachomatis infection, or substance abuse were not found to be significant independent risk factors. (Pediatr Res 28: 507-513, 1990)
\end{abstract}

\section{Abbreviations}

HPV, human papillomavirus

CIN, cervical intraepithelial neoplasia

STD, sexually transmitted disease

Despite the strong link between the development of cancer of the uterine cervix and infection with HPV (1-3), the exact role of HPV in the establishment of this cancer remains unknown. Several studies (4-11) have indicated that, in addition to HPV infection, cofactors are most likely required for cervical neoplasia to develop. These factors have included use of oral contraceptives, cigarette smoking, infection of the cervix with Chlamydia trachomatis or herpes simplex virus, and impaired immune response (4-11). Because most studies examining these factors

Received December 23. 1989: accepted June 19, 1990.

Correspondence and reprint requests: Dr. Barbara Moscicki, Division of Adolescent Medicine, University of California, San Francisco, 400 Parnassus Avenue, Rm. AC-01. San Francisco. CA 94143-0314.

Supported in part by funds provided by the Howard Hughes Medical Institute and the State of California and allocated on the recommendation of the Universitywide Task Force on AIDS, by an Academic Senate Grant. University of California, San Francisco. Bureau of Maternal and Child Health and Resource Development Training Grant no. MCJ000978, and by NIAID Grant IPO1A121912 and NCI CA35676.

1 This paper was awarded the Young Investigator Award for the Society of Adolescent Medicine. have been performed in populations with both HPV infection and neoplasia (i.e. dysplasia clinic populations), it has been difficult to differentiate cofactors associated with neoplasia from those associated with HPV infection. Distinguishing between the risk factors for HPV infection and those associated with progression to CIN or cancer is critical in understanding the pathogenesis of the disease because the risk factors may not be the same. Studies that examine populations with relatively early HPV infection, defined by a short exposure time, may be best suited for distinguishing these risk factors. Adolescents may serve as such a population because the rate of abnormal cytology in teens is lower than that found in older adult women, and adolescents have not been sexually active as long as most adult women. Therefore, the average time course from infection and acquisition of the virus to the gynecology clinic visit is expected to be less for the adolescent than for the older woman.

The purposes of our study were to determine the prevalence of HPV types $6,11,16,18,31,33$, and 35 among a sexually active adolescent female population and to identify factors associated with acquisition of these specific HPV types.

\section{SUBJECTS AND METHODS}

All sexually active females aged 13 to 19 y attending family planning clinics and having a pelvic examination for any reason on the day of the study were asked to participate. Sites consisted of an urban university-based adolescent gynecology clinic and two community-based family planning clinics, one urban and one surburban. Reasons for visits included family planning, STD complaints, pregnancy-related problems, and other gynecologic problems. Persons attending the family planning clinics were predominantly lower to middle class citizens. Most of those who attended these clinics were white $(60 \%)$; the rest were equally distributed among blacks (15\%), Hispanics (10\%), and other ethnic groups (15\%). Pregnant subjects were excluded from the study because pregnancy may independently alter the course or expression of HPV infection. Patients currently on antibiotics were also excluded because these drugs could alter results for STD. Informed consent was obtained as approved by the Committee on Human Research from all eligible subjects who attended the study after the nature of the procedures was explained to them. The refusal rate for entry into the study was $10 \%$. Information on race/ethnicity and clinic site was collected for those who refused. No differences were found between those who refused and those who participated for either of the variables.

History and physical examination. Subjects were given a selfadministered questionnaire to complete before examination. The questionnaire included information on sexual behaviors, type of contraceptive used within the past $60 \mathrm{~d}$ (more than one type could be reported) and frequency of its use using a 5-point scale (never/rarely/sometimes/usually/always), substance use and fre- 
quency, and STD history. Attempts to validate the self-reports on STD history were made by reviewing the medical record of those subjects who had attended the clinic previously. Socioeconomic status was measured by eliciting mother's highest level of education. Frequency of substance use was categorized into four response groups: never; used substance a few times per year; used substance at least once a month but less than once a week; and used substance at least once a week.

Routine gynecologic examination included gross visual inspection of the anogenital area for lesions consistent with condyloma acuminatum. The following were routinely obtained from each subject: exocervical and endocervical samples for Pap smear; exocervical and endocervical samples obtained on Dacron swabs for detection of HPV DNA; endocervical samples for culture of C. trachomatis and Neisseria gonorrhoeae; and vaginal samples for determination of $\mathrm{pH}$ and microscopic examination. Tests for herpes simplex virus, ectoparasites, syphilis, and other STD were performed when clinically indicated.

Microbiology. RNA-DNA hybridization. We used a commercially available RNA-DNA dot-blot hybridization technique [ViraPap (12), Bethesda Research Laboratories, Gaithersburg, MD] to identify HPV DNA. Procedure techniques for the HPV DNA detection kit were performed according to the manufacturer's recommendation (12). Cervical swabs for HPV were immediately placed into $1 \mathrm{~mL}$ of the sample transport medium and refrigerated at $4^{\circ} \mathrm{C}$ for no longer than 2 wk and at $-70^{\circ} \mathrm{C}$ if longer than $2 \mathrm{wk}$ before processing. Samples were processed as follows: samples were thawed to room temperature and were incubated after the addition of a bacterial protease. The swabs were then removed. The DNA was denatured by the addition of alkali and bound by filtration to a nylon membrane. The membrane-bound DNA was then hybridized to a mixture of radiolabeled probes that were specific for HPV types $6,11,16,18,31$, 33 , and 35 . The probe mixture consisted of $<5 \mu \mathrm{Ci}$ of ${ }^{32} \mathrm{P}$-labeled RNA probes prepared by in vitro transcription of recombinant plasmid containing substantially the entire DNA sequences of the seven HPV types. After hybridization, the nylon membrane was treated with ribonuclease to remove the unhybridized probe and washed under condition of high stringency (melting temperature $-10^{\circ} \mathrm{C}$ ) with $100 \mathrm{mM}$ PBS solution with $10 \mathrm{mM}$ EDTA and $1 \% \mathrm{wt} / \mathrm{vol}$ SDS. The presence of bound probe was detected by autoradiography of the membrane. High positive $[2 \times 1.0$ $\mathrm{mL}$ of $1 \times 10^{5} / \mathrm{mL}$ disrupted HeLa cells (a transformed human cervical cell line that contained HPV 18 DNA)], low positive (2 $\times 1.0 \mathrm{~mL}$ of $2 \times 10^{4} / \mathrm{mL}$ disrupted HeLa cells), and negative [2/ $1.0 \mathrm{~mL}$ of $5 \times 10^{5} / \mathrm{mL}$ disrupted HTB-31 cells (transformed human cervical cell line without HPV DNA)] controls were placed onto each membrane for comparison. Signals stronger or equal to the lower control were recorded as positive (Fig. 1). Signals weaker than the low control but stronger than the negative control were recorded as weakly positive. For filtration, a 25-well filter manifold (Bethesda Research Laboratories) was used that allowed for the processing of 22 samples and three controls per membrane.

All signals stronger than the negative control were prepared for typing. Unused portions of the samples positive for the HPV probe mixture were then studied (ViraType, Bethesda Research Laboratories) under similar conditions to determine the HPV type more precisely. Samples were filtered onto three separate membranes, and each membrane was then hybridized with one of three separate radioactively labeled probe mixtures: 1) types 6 and $11 ; 2$ ) types 16 and 18 ; and 3) types 31,33 , and 35. Each membrane had four controls, one for each typing group and one negative, to control for possible cross-hybridization reactions. Samples using the seven-probe mixture that had weakly positive dot-blot signals, yet had negative dot-blot signals using the three separate probes, were recorded as negative. Samples using the seven-probe mixture that had definitely positive signals, yet had negative dot-blot signals using the three separate probes, were recorded as "type undetermined."

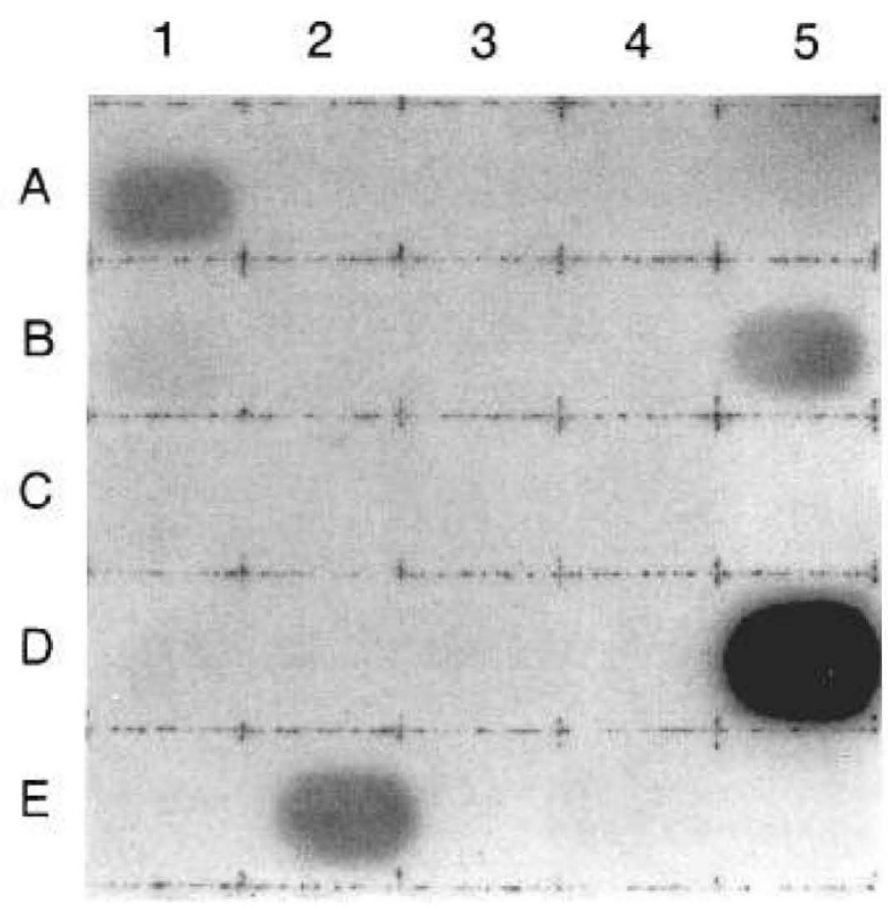

Fig. 1. Autoradiograph of ViraPap dot blot of cervical samples. $1 A=$ high control; $1 B=$ low control (very weak signal); $I C=$ negative control (see text for definitions). $2 E, 5 B$, and $5 D$ represent positive samples. Sample $5 B$ is the sample position in Figure 2, lane 13 and $5 D$ is the same sample positive in Figure 2, lane 11. Samples from $4 A, 4 B, 4 C, 4 D$, and $5 C$ represent negative samples in lanes $18,17,16,15,14$, and 12 in Figure 2, respectively. Other ViraPap samples identified on the blot were not included in this study.

Southern blot hybridization. Southern blot analyses, the current gold standard for HPV DNA detection, were performed on 79 samples not included in this study to validate the use of the RNA-DNA hybridization to detect HPV DNA in our population. Samples were randomly chosen from the three clinic sites described above. The cervical samples were first processed by the above described method. A similar aliquot $(250 \mu \mathrm{L})$ of the remaining digest was removed for Southern blot analysis.

Southern blot hybridization techniques for identification of HPV DNA have been described in detail (13). The $250 \mu \mathrm{L}$ of the dot-blot digest was placed into 1.5-mL Eppendorf tubes and a phenol/chloroform (3:1) extraction was performed. The DNA was then precipitated with $3 \mathrm{M} \mathrm{NaOAc}$ and isopropanol and the pellet was suspended in Tris-EDTA and then digested with PstI. After electrophoresis in a $1 \%$ agarose gel, the gel was depurinated in $0.25 \mathrm{~N} \mathrm{HCl}$, denatured in $0.5 \mathrm{~N} \mathrm{NaOH} / 1.5 \mathrm{M} \mathrm{NaCl}$, and neutralized in $0.5 \mathrm{M}$ Tris $\mathrm{pH} 7.5 / 3 \mathrm{M} \mathrm{NaCl}$. The DNA was transferred to a Hybond-N membrane using standard Southern assembly. The membranes were hybridized at high stringency (melting temperature $-10^{\circ} \mathrm{C}$ ) in $2 \mathrm{~mL}$ of $2 \times 10^{6} \mathrm{dpm} / \mathrm{mL} / \mathrm{probe}$ hybridization solution using a mixture of HPV $6,11,16,18,31$, 33 , and 35 . Autoradiograms were exposed $1 \mathrm{~d}$ and $2 \mathrm{wk}$ at $-70^{\circ} \mathrm{C}$ and were interpreted without knowledge of the RNA-DNA hybridization results. Only those specimens with a recognizable banding pattern were considered positive. Southern blot results were recorded as positive or negative (Fig. 2). Ten pg of each of the following unrestricted HPV DNA were added to the gel as hybridization controls: HPV 6, 11, 16, 18, 31, 33 (5.8-kb and $1.79-\mathrm{kb}$ fragments), and 35 (3.7-kb and $4.0-\mathrm{kb}$ fragments) (Fig. 2 ). Insufficient material was available for comparisons between Southern blot and the RNA-DNA hybridizations that used the three separate probe combination.

Samples for culture of C. trachomatis were placed into antibiotic-containing medium and refrigerated for $24 \mathrm{~h}$. Ten samples were refrigerated for $72 \mathrm{~h}$, which was considered still adequate 
123456789101112131415161718

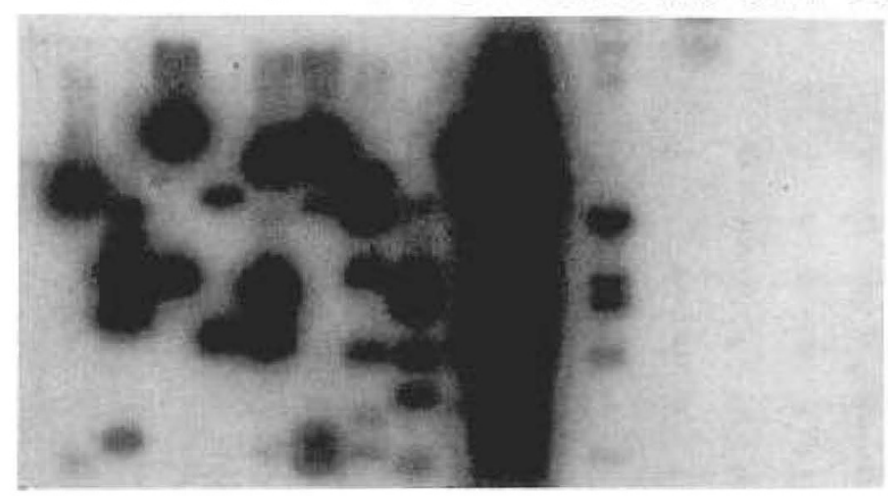

Fig. 2. Autoradiograph of Southern blot of cervical swab DNA digested with PstI. Lanes $1-10$ represent controls: lane 1, negative control pBR 322; lane 2, HPV 35 4.0-kb fragment; lane 3, HPV 35 3.7-kb fragment; lane 4, HPV 33 5.8-kb fragment; lane 5, HPV 33 1.79-kb fragment; lane 6, HPV 31; lane 7, HPV 18; lane 8, HPV 16; lane 9, HPV 11; lane 10, HPV 6. Lanes 11 and 13 represent positive samples. Lanes 12 , and $14-18$ were considered negative.

for culture by the university-based laboratory (4). All samples were then processed onto McCoy cell monolayers and incubated in cycloheximide-containing medium. Identification of positive cultures is described elsewhere in detail (4). N. gonorrhoeae samples were placed into charcoal medium and cultured by routine methods (14). Trichomonas vaginalis was diagnosed by detection on normal saline wet smears or by visualization on Pap smear.

Bacterial vaginosis was diagnosed if three of the following criteria were found on examination of vaginal fluid: 1 ) $\mathrm{pH}$ greater than $5 ; 2$ ) more than $20 \%$ clue cells; 3 ) fishy odor, detected when potassium hybroxide was added to vaginal samples; and 4) presence of a grey homogeneous discharge (15).

Cytology. Slides for cytology were immediately fixed in alcohol and prepared by standard methods (16). Slides for cytology were then sent to their respective routine cytology laboratories; one was university based, the other was a local private laboratory. Cytology was routinely screened by a cytotechnician and verified by a pathologist.

Cytologic diagnoses were categorized as benign, atypical, suggestive of condyloma, or suggestive of CIN with or without koilocytosis. The term CIN is used for easier reference although it is understood that cytology cannot determine the site of origin of neoplastic cells (e.g. cervical versus vaginal). Standard criteria were used to define CIN and condyloma (17). "Atypical" was diagnosed when rare abnormal cells (neoplastic or koilocytes) were found or when some, but not all, of the features of CIN or condyloma (koilocytosis) appeared on Pap smears.

Data analysis. Associations between the presence or absence of HPV cervical infection, as defined by DNA hybridization, and various relevant dichotomous variables were determined by the $\chi^{2}$ test or the Fisher exact test. For continuous variables, mean differences between those with and without HPV cervical infection were submitted to two-tailed $t$ tests. The level for statistical significance was set at 0.05 . Because little information is available with regard to risk for HPV infection in a population with a low prevalence of neoplasia, this level of significance allowed small effects to be detected. Tests were performed between those subjects with and without any HPV type and also between subjects with specific HPV groups: HPV types 6 and $11 ; 16$ and 18; and 31,33 , and 35. Those that had undetermined HPV types using ViraType were analyzed as a separate group. Statistical values are given for significant associations only.

The reported frequency of both oral contraceptive use and condom use varied widely ranging from "rarely" used to "always" used. Therefore, the oral contraceptive and condom use variables were categorized by frequency reported. This categorization reflected a more reasonable interpretation for the effect of the variable. Those who reported using the method "usually" or "always" were categorized as consistent users. The "sometime" users were initially analyzed separately but were found to have similar associations to the "never/rarely" group. Therefore, those who "never," "rarely," or only "sometimes" reported using the method were categorized as negative or nonusers.

Subjects' self-reports of a previous STD were considered to meet the criterion for a positive STD history. However, when the self-report contradicted the medical records, the subject's selfreport was preempted. These data are discussed in Results.

In the initial analyses, several variables were found to be significantly associated with HPV infection including number of lifetime sexual partners. Additional analyses were then performed to examine the relationship between number of sexual partners and other variables that were associated with HPV. These analyses included $\chi^{2}$ and $t$ tests. For those variables found to have a significant association with number of sexual partners, we re-examined their association with HPV infection by using a log linear analysis model [Logit (18)] to adjust for number of lifetime sexual partners. The model adjusts for number of lifetime sexual partners by applying a goodness of fit test [Likelihood Ratio $\left.\chi^{2}\left(\mathrm{~L}^{2}\right)\right]$. Significance is reported by the change in $\mathrm{L}^{2}\left(\Delta \mathrm{L}^{2}\right)$ between two models. The models examine the association between the specified variable and HPV infection independently of its association with number of lifetime sexual partners. A significant univariate association found with a nonsignificant multivariate association did not necessarily indicate that the variable was unrelated to HPV; rather, it implied that the association of the variable with HPV was not independent of its relationship to the number of lifetime sexual partners in the model.

The association between HPV infection including HPV groups and cytologic changes was assessed by $\chi^{2}$ tests. Because the number of subjects with CIN (2) was too small for analysis, subjects with CIN, condyloma, or atypia were collapsed into one category (abnormal) and compared with those subjects with normal cytology using $\chi^{2}$ tests. Descriptive information is reported on the distribution of HPV groups between those subjects with CIN, condyloma, atypia, and benign smears.

\section{RESULTS}

Sensitivity and specificity of the RNA-DNA hybridization technique. Table 1 shows the results of the Southern blot analysis compared with the dot-blot results. This table separates weakly positive from definitely positive dot-blot interpretations. Excluding the weakly positive, the sensitivity and specificity of the dot blot were 90 and $98 \%$, respectively. The overall sensitivity and specificity of the RNA-DNA hybridization, inclusive of the weakly positive samples, were 92 and $96 \%$, respectively (Fishers exact test; $p<0.001$ ).

Population description. Six-hundred sixty-one eligible adolescent females were enrolled in the study. The mean age was 17.1 y (SD 1.5). Racial distribution of the population was $52 \%$ white, $20 \%$ black, $13 \%$ Hispanic, and $15 \%$ other or mixed. Fifty-three percent reported that their mothers had graduated high school

Table 1. Comparison of ViraPap results to Southern blot analysis*

\begin{tabular}{lcc}
\hline & \multicolumn{2}{c}{ Southern blot } \\
\cline { 2 - 3 } & Positive & Negative \\
\hline ViraPap & & \\
Definite positive & 18 & 1 \\
Weakly positive $\dagger$ & 5 & 1 \\
Negative & 2 & 52 \\
\hline
\end{tabular}

$* p<0.001$.

$\dagger$ See text for definition. 
only and $47 \%$ reported that their mothers had at least some college experience. Three quarters of the subjects had been seen for family planning reasons; the rest had been seen for STDrelated complaints. The mean age of menarche was 12.5 y (SD 1.3).

One-hundred two subjects (15\%) were positive for HPV DNA. Of those subjects positive for a single HPV DNA group, 24 were positive for HPV types 6 or 11,38 for types 16 or 18 , and 16 for types 31,33 , or 35 . Specimens from nine subjects were positive for two or more HPV groups: six subjects for types 16 or 18 and 31,33 , or 35 , two for types 6 or 11 and 16 or 18 , and one for all three groups. The HPV type of 15 strongly positive dot-blot samples could not be determined adequately by the ViraType technique. There were no significant differences between subjects with and without HPV or among HPV type group for age, race, socioeconomic status, reason for visit, or age of menarche.

Prevalence for HPV DNA, mother's level of education, age, reason for visit, and race were found to be similar for the nonuniversity clinics $(n=608)$ and university-based clinic populations. Because prevalences of HPV were similar and demographic characteristics did not differ between sites, the clinic sites were not separated for analysis.

Sexual behaviors. No differences were found between those with and without HPV for age of sexual debut (mean $y=15.2$ (SD 1.7) or number of years sexually active (mean y $=2.0$ (SD 1.7). However, subjects who had HPV cervical infection had more lifetime sexual partners than those who did not $\left(\chi^{2}=24.5\right.$; $p<0.001$ after Yates correction) (Table 2). In contrast, the groups did not differ in the number of sexual partners within the $60 \mathrm{~d}$ preceding the study. Eighty percent of subjects reported having either none or one sexual partner in the past $60 \mathrm{~d}$. Within the group of subjects with HPV cervical infections, the specific HPV DNA group identified was not associated with the number of recent or past sexual partners (data not shown).

Contraception method. Many of the adolescents reported using more than one type of contraception in the past $60 \mathrm{~d}$. Forty-four percent of subjects reported having used oral contraceptives sometime during the past $60 \mathrm{~d}$. Condoms, diaphragms, nonvaginal intercourse, (anal or oral sex) and foam were used by 52 , 6,15 , and $3 \%$, respectively. Forty-one percent reported having used nothing at least once in the past $60 \mathrm{~d}$. No differences were found between the reported use of these methods and presence or absence of HPV. To examine the effect of oral contraceptive use more carefully, we identified those who reported using oral contraceptives consistently in the past $60 \mathrm{~d}$ and no other method. Of those who used only oral contraceptives and used them consistently, 12 of 49 (26\%) were positive for HPV; of those who did not fall into this category (which included those reporting another method used either in combination with oral contraceptives or alone) 87 of $592(15 \%)$ were positive for HPV $\left(\chi^{2}=\right.$ $3.400 ; p=0.03$ ). Only $3 \%$ of subjects reported consistent use of condoms as their only method of birth control; no difference was found between those with and without HPV. Seventeen percent of subjects reported using both oral contraceptives and condoms at varying frequencies. Consistent users of both were too small to analyze.

After adjusting for number of lifetime partners, consistent oral contraceptive use was no longer significantly associated with

Table 2. Reported sexual behavior*

\begin{tabular}{lcc}
\hline & HPV + & HPV- \\
\hline No. of lifetime partners $\dagger$ & & \\
$1-3$ & $39(39 \%)$ & $354(64 \%)$ \\
$4-10$ & $41(40 \%)$ & $142(26 \%)$ \\
$11-25$ & $18(18 \%)$ & $44(8 \%)$ \\
$>25$ & $3(3 \%)$ & $13(2 \%)$ \\
\hline
\end{tabular}

* Some subjects did not answer all the questions, thus the denominators vary.

$+p<0.001$.
HPV cervical infection $\left(\Delta \mathrm{L}^{2}=1.67, d f(1) ; p=0.8\right)$. No differences were found for HPV group for any of the methods described.

STD history. There was no difference between subjects with and without HPV cervical infection for any current STD infection (Table 3). However, when the prevalence of a past history of an STD was analyzed, those with HPV were more likely to have a history of $C$. trachomatis than those without HPV $\left(\chi^{2}=\right.$ $3.58 ; p=0.05$ ) (Table 3). Of those with a history of $C$. trachomatis infection, $24 \%$ ( 16 of 68 ) were positive for HPV compared with $15 \%$ (86 of 584) of those without a history of C. trachomatis. However, after adjustment was made for number of lifetime sexual partners, a past history of $C$. trachomatis infection was no longer significantly associated with $\mathrm{HPV}\left(\Delta \mathrm{L}^{2}=0.91, d f(1), p=\right.$ 0.65 ).

Not unexpectedly, condyloma acuminatum was also more likely to have been recognized at some time among those with HPV than among those without $\left(\chi^{2}=18.83 ; p<0.001\right)$. The specific HPV DNA group detected was not associated with any of the tested STD. However, $58 \%$ of those with type 6 or 11 had a past or current history of condyloma acuminatum compared with $22 \%$ of those with types $16,18,31,33$, or 35 [the rest $(13 \%)$ were untypeable] ( $p=0.001$, data not shown). Adequate information on herpes simplex virus infections was not available for analysis because the virus was not cultured routinely. By history and clinical symptoms, only three subjects had a past or current history.

Reliability of STD reporting. For the 293 subjects for whom two sources of data were available, there was a $93 \%$ agreement overall between the positive and negative self-reports of a STD and medical records. However, many of the adolescents may have sought care at other institutions; thus, the negative medical chart findings in those with a positive reported history may not be reliable. More specifically, the medical records of 20 of 39 (51\%) of those who reported a history of C. trachomatis and 20 of $29(69 \%)$ of those reporting $N$. gonorrhoeae contained verifications by culture or fluorescent antibody technique. In addition, three of eight reported cases (38\%) of herpes simplex virus infection, 31 of 48 cases $(65 \%)$ of external warts, and 15 of 21 cases $(71 \%)$ of $T$. vaginalis were verified. For the 248 subjects reporting no history of an STD for whom medical records were available, the overall agreement between self-report and medical records was $98 \%$. Of those not reporting $C$. trachomatis, $N$. gonorrhoeae, herpes simplex virus, $T$. vaginalis, or warts, between 95 and $98 \%$ were verified by their medical records. More specifically, $5,4,7,3$, and $2 \%$ of those who reported a negative history for $C$. trachomatis, $N$. gonorrhoeae, herpes simplex virus, $T$. vaginalis, or warts, respectively, had a positive history by chart.

Substance use. Cigarette use was not associated with HPV infection of the cervix; 32 of 87 subjects with HPV (37\%) reported current cigarette use, compared with 153 of $468(33 \%)$ of those without HPV $(p=0.5)$. No differences occurred for history of past cigarette use, number of cigarettes smoked per day, and past months of cigarette use between those with and without HPV (data not shown). In contrast, marijuana was used more frequently among subjects with HPV than among those without $\left(\chi^{2}=9.19 ; p=0.05\right)$ (Table 4). Subjects with HPV appeared more likely to use other drugs (including cocaine, amphetamines, and Quaaludes) as well $\left(\chi^{2}=13.91 ; p=0.008\right)$. After we adjusted for number of lifetime sexual partners, marijuana use or drug use was no longer significantly associated with HPV cervical infection $\left(\Delta \mathrm{L}^{2}=5.51, d f(4), p=0.8\right.$ and $\Delta \mathrm{L}^{2}=$ $3.28, d f(4), p=0.5$, respectively). HPV group was not associated with frequency of substance use.

Cytology. Cytologic diagnoses were available for 616 subjects (96 HPV positive and $520 \mathrm{HPV}$ negative subjects). Of the 96 subjects with HPV, 73 (76\%) had benign Pap smears, four had smears suggestive of condyloma, one had a smear with low-grade CIN with koilocytosis, one had a smear with low-grade CIN 
Table 3. History of STD in subjects with and without HPV cervical infections

\begin{tabular}{|c|c|c|c|c|}
\hline & \multicolumn{2}{|c|}{$\mathrm{HPV}+$} & \multicolumn{2}{|c|}{ HPV- } \\
\hline & $\begin{array}{l}\text { With current } \\
\text { history (\%) }\end{array}$ & $\begin{array}{c}\text { With past } \\
\text { history* }(\%)\end{array}$ & $\begin{array}{c}\text { With current } \\
\text { history (\%) }\end{array}$ & $\begin{array}{c}\text { With past } \\
\text { history* }(\%)\end{array}$ \\
\hline C. trachomatis & 10 & $16 \dagger$ & 10 & $10 \dagger$ \\
\hline N. gonorrhocae & 2 & 14 & 3 & 8 \\
\hline T. vaginalis & 2 & 7 & 4 & 6 \\
\hline Condyloma acuminatum & $18 \div$ & $21 \ddagger$ & $3 \ddagger$ & $7 \ddagger$ \\
\hline Bacterial vaginosis§ & 11 & $\mathrm{NA} \|$ & 8 & $\mathrm{NA} \|$ \\
\hline
\end{tabular}

* Included the presence of either a reported history of infection or a positive STD history from the medical chart.

$\dagger p=0.05$.

$\ddagger p<0.001$.

$\S$ Not necessarily considered an STD.

|| Data not available.

Table 4. History of substance use*

\begin{tabular}{lcc}
\hline & HPV+ & HPV- \\
\hline Marijuana use $\dagger$ & & \\
None presently $\ddagger$ & $30(31 \%)$ & $159(30 \%)$ \\
Never & $24(25 \%)$ & $181(33 \%)$ \\
Few times/y & $10(10 \%)$ & $79(15 \%)$ \\
$\geq$ Once/mo but <once/wk & $21(22 \%)$ & $67(13 \%)$ \\
$\geq$ Once/wk & $12(12 \%)$ & $48(9 \%)$ \\
& & \\
Other drug use $\S$ & & \\
None presently $\$$ & $11(12 \%)$ & $41(8 \%)$ \\
Never & $57(59 \%)$ & $409(76 \%)$ \\
Few times/y & $14(15 \%)$ & $47(9 \%)$ \\
$\geq$ Once/mo but <once/wk & $9(9 \%)$ & $30(5 \%)$ \\
$\geq$ Once/wk & $5(5 \%)$ & $9(2 \%)$ \\
\hline
\end{tabular}

* Several subjects did not answer these questions, thus denominators vary.

$\dagger p=0.05$.

$¥$ Past history of drug use, but none currently.

$\S p<0.008$.

without koilocytosis, and 17 had atypical Pap smears. In contrast, of those 520 without HPV, $498(96 \%)$ had benign smears, three had smears suggestive of condyloma, none had CIN, and 19 had atypicals $\left(\chi^{2}=50.816 ; p<0.001\right.$ after Yates correction). When we compared differences between normal and abnormal cytology, we found that 23 of $45(51 \%)$ of our subjects who had an abnormal Pap smear were positive for HPV DNA compared with 73 of $571(13 \%)$ of those subjects who had a normal Pap smear $\left(\chi^{2}=47.62 ; p<0.001\right)$. The following describes the distribution of HPV groups for those subjects positive for HPV between cytologic diagnoses. Of those who had benign smears $(n$ $=73$ ), $22 \%$ were positive for group $6 / 11,60 \%$ for group $16 / 18 /$ $31 / 33 / 35$, and the rest were undetermined. Of those with cytologic changes suggestive of condyloma $(n=4), 50 \%$ were positive for group $6 / 11$, and $50 \%$ for group $16 / 18 / 31 / 33 / 35$. Of those with atypia $(n=17), 35 \%$ were positive for group $6 / 11,65 \%$ for group $16 / 18 / 31 / 33 / 35$, and the rest were undetermined. Of the two subjects with CIN, one was positive for group 16/18/31/33/ 35 and one was undetermined. For comparison, $33 \%$ of those with type 6 or 11 and $24 \%$ of those with type $16,18,31,33$, or 35 had abnormal smears. No differences between the HPV groups and cytologic diagnosis (normal versus abnormal) were found.

\section{DISCUSSION}

Our study indicates that HPV is the most prevalent sexually transmitted organism in our adolescent female population, having been detected in $15 \%$ of subjects between the ages of 14 and $19 \mathrm{y}$. In addition, the predominant HPV types detected were the cancer-related types $16,18,31,33$, and 35 . Previous studies that have reported other sexually transmitted organisms as the most common causes of genital infections among adolescents did not identify HPV infections by the appropriate laboratory methods $(19,20)$.

Rosenfeld et al. (21) reported a higher rate (38\%) of HPV infection among adolescent females. However, their study was performed in a population of predominantly inner-city youth, who had documented high rates of STD infections and unplanned pregnancies in the study. Also, their method of collection using cervical lavages was more likely to identify vaginal and vulvar disease than our use of cervical swabs. Lastly, their study employed the Southern blot hybridization technique, which when performed at low stringency can determine if DNA of any papillomavirus is present (22).

Our study used a standardized dot-blot technique, with sensitivities and specificities equivalent to that of Southern blot hybridization for the HPV types being sought. This technique was performed under conditions of high stringency, resulting in identification of the HPV DNA types specified by the probe mixture only (types $6,11,16,18,31,33$, and 35). Comparatively, under high stringent conditions, Rosenfeld's study showed a similar prevalence rate $(12 \%)$ as ours for types $6,11,16$, and 18 . However, under low stringent conditions with probes specifically for types $6,11,16$, and $18,67 \%$ of their positive HPV group had uncharacterized HPV types. Contrary to other studies $(1-3,23$, $24)$, this suggests that non-6, 11, 16, 18 HPV types were the predominate types found in their population. Similar to our findings, Martinez et al. (25) reported that $13 \%$ of their innercity sexually active adolescent females were positive for HPV DNA using low-stringency Southern blot analysis and only $16 \%$ of the samples were considered uncharacterized. This finding compared with Rosenfeld's may reflect the recently reported lack of standardization and reproducibility associated with Southern blot analysis for HPV DNA detection (26).

Prevalence rates reported in adult women are also difficult to compare because methods of HPV DNA detection vary from study to study. Kiviat et al. (27), using a combination of a dot blot and Southern hybridization to detect types $6,11,16,18$, and 31 , reported a slightly lower prevalence than in our population for HPV DNA in women attending either an STD clinic $(11 \%)$ or a college study health clinic $(9 \%)$. de Villiers et al. (28), using a filter in situ hybridization technique, found that $10 \%$ of women aged less than $20 \mathrm{y}$ and attending outpatient clinics in a German university were positive for HPV DNA types $6,11,16$, and 18. However, they also found that women older than $50 \mathrm{y}$ had a prevalence rate of less than $5 \%$.

This information in regard to the higher prevalence of HPV in populations of adolescents than in older women suggests that adolescents may be at higher risk for HPV infection. It has been postulated that the biologic immaturity of the cervix associated with normal adolescent development may leave the adolescent cervix vulnerable to STD infection including HPV $(29,30)$. In a previous study, we noted that biologic immaturity measured by 
age of menarche was associated with CIN in adolescents (31). The lack of the association between HPV infection and menarcheal age in this study may reflect the importance of biologic immaturity in the role of neoplastic development rather than HPV infection inasmuch as the rate of neoplasia $(0.3 \%)$ was extremely low in our group.

Risk factors associated with cervical neoplasia have included multiple sexual partners, use of oral contraceptives, $C$. trachomatis infection, menarcheal age, and cigarette smoking (4-6, 31-33). In our study, all of these cofactors except cigarette smoking and menarcheal age were associated with HPV infection using univariate analysis only. A history of multiple sexual partners was strongly associated with HPV infection, as has been reported for other STD $(32,33)$. This most likely reflects multiple exposures to HPV-infected consorts. On the other hand, the number of sexual partners in the past $60 \mathrm{~d}$ did not differ between HPV-infected and noninfected subjects, possibly due to the relative insensitivity of the dot blot for detecting low viral copy numbers, which may be present early in the course of transmission and infection.

It has been suggested that hormones play an important role in the course of HPV infection, perhaps by establishing an appropriate cervical milieu or by enhancing viral replication $(1,5,6$, 34). Others have indicated that $C$. trachomatis infection may create a desirable milieu for HPV by disruption of the cervical barrier and reparative stimulation of cell division $(2,35)$. Our univariate analysis originally suggested that a specific sequence of events may increase the risk for HPV infection because past history of $C$. trachomatis rather than current history alone was positively associated with detection of HPV DNA. Our ability to draw meaning from history of past infection is limited in this study because of its dependence on subject reporting. However, both oral contraceptive use and $C$. trachomatis infection were no longer associated with HPV infection in the multivariate analysis, suggesting that these risk factors are not independent of sexual lifestyles.

Substance use has not previously been identified as a risk for CIN development. However, the literature lacks studies that have specifically examined this association. We hypothesized that significant substance use may be related to depression of the host immune response and may play an important role in infection and possibly neoplastic development $(36,37)$. Our study found that frequent substance use was univariately associated with HPV infection; however, it was no longer statistically significant after we adjusted for multiple partners.

Cigarette use has also been reported as a significant risk factor for CIN (38). As with menarcheal age, the lack of a positive association between cigarette use and HPV infection in our population underscores the need to differentiate between risk factors for HPV infection and those for CIN.

The lack of significant abnormal pathology on Pap smears in our adolescent subjects reflects the validity of studying this population to identify specific risk factors for HPV infection before the onset of high-grade neoplastic lesions. However, it is well recognized that cytology remains an insensitive tool for diagnosing neoplasia (39), and that a more sensitive test such as colposcopy and histology must be used to correctly differentiate those women with and without neoplasia. Therefore, this study did not attempt to differentiate these groups for risk factors.

In summary, our study shows the cancer-related HPV types are common sexually transmitted pathogens among adolescents. The only risk factor identified for HPV infection was related to sexual behavior. Use of oral contraceptives, history of $C$. trachomatis infection, and frequent substance use may be related to the acquisition of HPV; however, we were unable to demonstrate that these factors were independent from choice of sexual lifestyles. With the exception of smoking and late menarcheal age, this list of risk factors appears similar to those risk factors associated with CIN. This suggests that certain factors associated with CIN may in fact reflect their role in the establishment of
HPV infection rather than a direct association with the development of neoplasia. Because the interrelationship between behaviors and infections is complex and neoplasia is a timedependent event, only longitudinal studies can distinguish these differences. In addition, standardization of tests for investigational use remains critical.

Acknowledgments. The authors thank Dulce Padilla, Tracy Suitt Keogh, Roy Rodriguez, and Margot Duxler for their help in preparing the manuscript and Jenny Broering and Tom Sinclair for their assistance in data collection. Probes and control for HPV type 35 were kindly provided by Bethesda Research Laboratories.

\section{REFERENCES}

1. Broker TR, Botchan M 1986 Papillomaviruses: retrospectives and prospectives cancer cells 4. Cold Spring Harbor Laboratory, Cold Spring Harbor, NY, pp 17-36

2. McCance DJ, Campion MJ, Clarkson PK, Chesters PM, Jenkins D, Singer A 1985 Prevalence of human papillomavirus type 16 DNA sequences in cervical intraepithelial neoplasia and invasive carcinoma of the cervix. $\mathrm{Br} \mathrm{J}$ Obstet Gynaecol 92:1101-1105

3. Durst M, Gissman L, Ikenberg H, Zur Hausen H 1983 A papillomavirus DNA from a cervical carcinoma and its prevalence in cancer biopsy samples from different geographic regions. Proc Natl Acad Sci USA 80:3812-3815

4. Schachter J, Hill EC, King EB, Heilbron DC, Ray RM, Margolis AJ, Greenwood SA 1982 Chlamydia trachomatis and cervical neoplasia. JAMA 248:2134-2138

5. Daling JR, Sherman KJ, Weiss NS 1986 Risk factors for condyloma acuminatum in women. Sex Transm Dis 13:16-18

6. Clarke EA, Hatcher J, McKeown-Eyssen GE, Lickrish GM 1985 Cervical dysplasia: association with sexual behavior, smoking, and oral contraceptive use? Am J Obstet Gynecol 151:612-616

7. Zur Hansen H 1982 Human genital cancer: synergism between two virus infections or synergism between a virus infection and initiating events? Lancet 2:1370-1372

8. Dietl J, Semm K, Hedderich J, Buchholz F 1983 CIN and preclinical cervical carcinoma. A study of morbidity trends over a 10 -year period. Int J Gynaecol Obstet 21:283-289

9. Zelnik M, Kanter JF 1980 Sexual activity, contraceptive use and pregnancy among metropolitan-area teenagers. Fam Plann Perspect 12:230-237

10. Maw RD, Hanley O 1983 Cervical cytology figures for 1970-81. [letter] Br J Vener Dis 59:408-409

11. Sadeghi SB, Hsieh EW, Gunn SW 1984 Prevalence of cervical intraepithelial neoplasia in sexually active teenagers and young adults. Results of data analysis of mass Papanicolaou screening of 796,337 women in the United States in 1981. Am J Obstet Gynecol 148:726-729

12. ViraPap ${ }^{\circledR}$ Human Papillomavirus (HPV) DNA Detection Kit and ViraType ${ }^{\odot}$ HPV DNA Typing Kit Manuals 1989 Life Technologies, Bethesda Research Laboratories, Gaithersburg, MD

13. Lorincz AT 1987 Detection of human papillomavirus infection by nucleic acid hybridization. Obstet Gynecol Clin North Am 14:451-469

14. Lennette EH, Balows A, Hausler WJ, Truant JP (eds) 1980 Manual of Clinical Microbiology, 3rd Ed. American Society for Microbiology, Washington, DC

15. Amsel R, Totten PA, Spiegel CA, Chen KC, Eschenbach D, Holmes KK 1983 Nonspecific vaginitis: diagnostic criteria and microbial and epidemiologic associations. Am J Med 74:14-22

16. Danos M, Keebler CM 1975 Cytopreparatory techniques. In: Keebler CM, Reagan JW (eds) A Manual of Cytotechnology, 4th Ed. American Society of Pathologists, Chicago, pp 266-269

17. Ferenzy A, Winkler B 1987 Cervical intra-epithelial neoplasia and condyloma. In: Kurman RJ (ed) Blaustein's Pathology of the Female Genital Tract, 3rd Ed. Springer-Verlag, New York, pp 177-217

18. Knoke P, Burke PJ 1980 Log-Linear Models. Sage Publications, Beverly Hills

19. Moscicki B, Shafer MA, Millstein SG, Irwin Jr CE, Schachter J 1987 The use and limitations of endocervical Gram stains and mucopurulent cervicitis as predictors for Chlamydia trachomatis in female adolescents. Am J Obstet Gynecol 157:65-71

20. Mascola L, Albritton WL, Cates Jr W, Reynolds GH 1983 Gonorrhea in American teenagers, 1960-1981. Pediatr Infect Dis J 2:302-303

21. Rosenfeld WD, Vermund SH, Wentz SJ, Burk RD 1989 High prevalence rate of human papillomavirus infection and association with abnormal Papanicolaou smears in sexually active adolescents. Am J Dis Child 143:1443-1447

22. Roman A, Fife KH 1989 Human papillomaviruses: are we ready to type? Clin Microbiol Rev 2:166-190

23. Reid R, Greenberg M, Jenson AB, Husain M, Willett J, Daoud Y, Temple GF, Stanhope CR, Sherman A, Phibbs G, Lorincz AT 1987 Sexually transmitted papillomaviral infections $I$. The anatomic distribution and pathologic grade of neoplastic lesions associated with different viral types. Am J Obstet Gynecol 156:212-222

24. Gissmann L, de Villiers EM, Zur Hausen H 1982 Analysis of human genital warts (condylomata acuminata) and other genital tumors for human papillomavirus type 6 DNA. Int J Cancer 29:143-146 
25. Martinez J, Smith R, Farmer M, Resau J, Alge L, Daniel L, Gupta J, Shah K, Naghashfar Z 1988 High prevalence of genital tract papillomavirus infection in female adolescents. Pediatrics 82:604-608

26. Brandsma J, Burk RD. Lancaster WD, Pfister H, Schiffman MH 1989 Interlaboratory variations as an explanation for varying prevalence estimates of human papillomavirus infection. Int J Cancer 43:260-262

27. Kiviat NB, Koutsky LA, Paavonen JA, Galloway DA, Critchlow CW, Beckmann AM, McDougall JK, Peterson ML, Stevens CE, Lipinski CM, Holmes KK 1989 Prevalence of genital papillomavirus infection among women attending a college study health clinic or a sexually transmitted disease clinic. J Infect Dis 159:293-302

28. de Villiers E-M, Wagner D, Schneider A, Wesch H, Miklaw H, Wahrendorf J, Papendick U, zur Hausen H 1987 Human papillomavirus infections in women with and without abnormal cervical cytology. Lancet 2:703-706

29. Singer A 1976 The cervical epithelium during puberty and adolescence. In: Jordan JA, Singer H (eds) The Cervix. Saunders, Philadelphia, p 87-104

30. Andrews FJ, Linehan JJ, Melcher DH 1978 Cervical cancer in younger women. Lancet 2:776-778

31. Moscicki B, Winkler B, Irwin C, Schachter J 1989 Differences in sexual behavior, contraception and biologic maturation in adolescents with and without cervical intraepithelial neoplasia. J Pediatr 115:487-493

32. Rotkin ID 1973 A comparison review of key epidemiological studies in cervical cancer related to current searches for transmissible agents. Cancer Res 33:1353-1367

33. Guijon FB, Parasekevas M, Brunham R 1985 The association of sexually transmitted diseases with cervical intraepithelial neoplasia: a case-contro study. Am J Obstet Gynecol 151:185-190

34. Kreider JW, Zaino R, Welsh PA, Patrick SD 1989 Host factors regulating condylomatous transformation by HPV-11. J Cell Biochem [Suppl] 13C:179(abstr)

35. Wahl RW 1984 Chlamydia, repair and intraepithelial neoplasia. [letter] Acta Cytol 28:89

36. Lutzner MA 1985 Papillomavirus in immunodepression and immunosuppression. Clin Dermatol 3:165-169

37. Medhus A 1975 Venereal diseases among female alcoholics. Scand J Soc Med 3:28-33

38. Greenberg ER, Vessey M, McPherson K, Yeates D 1985 Cigarette smoking and cancer of the uterine cervix. Br J Cancer 51:139-141

39. Shulman JJ, Leyton M, Hamilton R 1974 The Papanicolaou smear: an insensitive case-finding procedure. Am J Obstet Gynecol 120:446-451.

\section{Announcement}

\section{Call for Abstracts}

The American Pediatric Society and The Society for Pediatric Research announce the abstract deadline for the 1991 Annual Meeting (April 29-May 2, 1991, New Orleans Hilton \& Rivergate Convention Center, New Orleans, LA) has been set as January 3, 1991. For further information contact: 2650 Yale Blvd., S.E., Suite 104, Albuquerque, NM 87106, (505)764-9099, FAX (505)842-8227. 